Tropical Journal of Pharmaceutical Research June 2015; 14 (6): 1049-1055

ISSN: $1596-5996$ (print); 1596-9827 (electronic)

(C) Pharmacotherapy Group, Faculty of Pharmacy, University of Benin, Benin City, 300001 Nigeria.

All rights reserved.

Available online at http://www.tjpr.org

Original Research Article

http://dx.doi.org/10.4314/tjpr.v14i6.16

\title{
Effects of Ganoderma lucidum Spent Mushroom Substrate Extract on Milk and Serum Immunoglobulin Levels and Serum Antioxidant Capacity of Dairy Cows
}

\author{
Yanling Liu ${ }^{1,2}$, Chao Zhao,3, Dongmei Lin ${ }^{1}$, Haijuan Lan ${ }^{4}$, Zhanxi Lin ${ }^{1,2 *}$ \\ ${ }^{1}$ College of Life Science, Fujian Agriculture and Forestry University, ${ }^{2}$ National Engineering Research Center of Juncao, Fuzhou, \\ Fujian 350002, ${ }^{3}$ College of Food Science, ${ }^{4}$ ChangFu Dairy of Fujian Co., Ltd, Nanping, Fujian 353000, China \\ *For correspondence: Email: Izxjuncao@163.com; Tel: 86-591-83789223; Fax: 86-591-83768494
}

Received: 12 December 2014

Revised accepted: 25 May 2015

\begin{abstract}
Purpose: To investigate the effects of Ganoderma lucidum hot water extract (HWE) from spent mushroom substrate on milk and serum immunoglobulin levels and serum antioxidant capacity.

Methods: Forty cows within the same parity and stage of lactation and with similar body weight were randomly divided into four groups of 10 cows each. The daily dietary dosage of HWE was $0,33,67$, and $100 \mathrm{~g}$ for control and the three experimental groups EG1, EG2, and EG3, respectively. Serum antioxidant activity as well as milk and serum immunoglobulin levels were measured by enzyme-linked immunosorbent assay (ELISA).

Results: After administration for 60 days, no significant differences in milk IgG, $\lg A$, or $\lg M$ concentrations were detected among the experimental groups, but serum IgA concentration was significantly higher in EG1, EG2, and EG3 groups compared with control group $(p<0.01)$. Additionally, significant differences were detected in serum total antioxidant capacity (TAC) and mean serum TAC concentration among control, EG1, EG2, and EG3 groups ( $p<0.05)$.

Conclusion: The results suggest that when utilized as a feed additive, HWE may enhance immunity and antioxidant capacity in dairy cows, and subsequently improve milk quality.
\end{abstract}

Keywords: Ganoderma lucidum, Spent mushroom substrate, Immunoglobulin, Antioxidant capacity, Dairy cows

Tropical Journal of Pharmaceutical Research is indexed by Science Citation Index (SciSearch), Scopus, International Pharmaceutical Abstract, Chemical Abstracts, Embase, Index Copernicus, EBSCO, African Index Medicus, JournalSeek, Journal Citation Reports/Science Edition, Directory of Open Access Journals (DOAJ), African Journal Online, Bioline International, Open-J-Gate and Pharmacy Abstracts

\section{INTRODUCTION}

Following rapid advances in animal husbandry, the use of feed additives for the improvement of animal production and performance has become more widespread. Consequently, the use of additional chemicals including carcinogenic and teratogenic agents, as well as the increased use of antibiotics has led to issues related to pesticide residues and drug resistance, respectively. Conversely, Chinese herbal medicine feed additives have gradually gained acceptance, and are not associated with residues or drug resistance.

The long history regarding the use of Chinese herbal medicine is supported by extensive literature and clinical applications that span thousands of years [1]. Further, Chinese herbal medicine feed additives have noted resistance and anti-toxin effects, meet the quality standards for healthy food, and are thought to improve immunity. In particular, the polysaccharides from Ganoderma mushrooms are reported to possess 
a wide range of bioactivities, including immune modulation and antitumor effects [2,3], as well as anti-atherosclerosis, anti-diabetic, and anti-aging activities [4].

Due to the enzymatic conversion processes that occur during mushroom cultivation, ruminants can easily digest spent mushroom substrate (SMS) [5,6]. Consequently, SMS may be an appropriate feed additive for sheep [7] and Holstein steers [8]. Following harvest, many nutritional ingredients remained in the SMS. Nevertheless, only a few reports exist on the application and benefits of SMS from the cultivation of Ganoderma lucidum (G. lucidum; SMSG) as a feed additive for livestock $[9,10]$.

The main objective of this study was to determine the effect of hot water extract (HWE) from SMSG generated following cultivation of $G$. lucidum using the JUNCAO technique on milk and serum immunoglobulin concentrations, and on serum antioxidant capacity in dairy cows. The results of this study could provide a foundation for the development of SMSG feed additive products.

\section{EXPERIMENTAL}

\section{Fungal strain and SMSG hot water extraction}

G. lucidum (Leyss ex fr) Karst (Lingzhi in Chinese) was provided by National Engineering Research Center of JUNCAO Technology (Fuzhou, China) and was cultivated with JUNCAO technique. JUNCAO research began at the Fujian Agriculture and Forestry University in 1986. Subsequently, evidence has indicated that fungal species cultivated using the JUNCAO technique are high quality materials for $G$. lucidum cultivation. JUNCAO (JUN: fungus, CAO: grass in Chinese) is defined as the herbaceous plants that are suitable for cultivating edible and medicinal fungi [11]. Under certain suitable conditions, the germination to harvest cycle of $G$. lucidum can be performed in 4-5 weeks using JUNCAO technology.

After the harvest of G. lucidum, the fresh SMSG were collected, and then extracted in boiling water for $4 \mathrm{~h}$ in the ratio 10:1 (v/w) water to raw materials, and then filtered. The remaining SMSG residue was collected and extracted in boiling water for $3 \mathrm{~h}$ at an $8: 1(\mathrm{v} / \mathrm{w})$ ratio of water to raw materials two additional times. Last, the supernatant was concentrated under $0.09 \mathrm{MPa}$ conditions at a temperature maintained at $55-65$ ${ }^{\circ} \mathrm{C}$. Ten kilograms HWE were obtained from 100 $\mathrm{kg}$ fresh SMSG, and the HWE powders were produced using the spray drying process. The final composition of HWE is $23.58 \%$ crude protein, $17.60 \%$ ash, $4.95 \%$ amino acid and 2.0 $\mathrm{g} / \mathrm{kg}$ crude fat, $6.0 \mathrm{~g} / \mathrm{kg}$ crude fiber.

\section{Animals}

The 40 Holstein cows involved in this study were cared for in accordance with the guidelines of Agricultural Industry Standards of the People's Republic of China-Feeding Standard of Dairy Cattle (NY/T 34-2004). Prior to initiation of the study, all Holstein cows (Table 1) were housed for two weeks for the purposes of environmental adaptation in individual tie-stalls outfitted with rubber mattresses. All cows had ad libitum access to drinking water and were fed a total mixed ration (TMR) diet (Table 2) under controlled conditions (temperature $24.0 \pm 0.5^{\circ} \mathrm{C}$, humidity $55.0 \pm 5.0 \%$ ) for the duration of the study. The TMR was mixed using a UNIFAST vertical cutter-mixer wagon (20 litres; Trestina, Italy), and the final moisture content was $51 \%$.

The cows were randomly divided into four groups of 10 cows each (Control, EG1, EG2, and EG3).HWE dosages for the three experimental groups was 33, 67, and $100 \mathrm{~g} / \mathrm{d} / \mathrm{cow}$, and 0 $\mathrm{g} / \mathrm{d} / \mathrm{cow}$ fort the control group. Using HWE as a feed additive was conducted for 60 days. This study was approved and conducted in accordance with the standards (009135) established by ChangFu Dairy of Fujian Co., Ltd. (Nanping, Fujian, China), which served as the experimental test site. ChangFu Dairy personnel collected samples from the dairy cows over the course of the study according to the institutional and national guidelines for the care and use of animals. Finally, all experimental procedures involving animals were conducted in accordance with the guidelines established by the China Managements on Experimental Animal Care [12].

Table 1: Some baseline parametersof the tested dairy cows before experiment

\begin{tabular}{lccc}
\hline Treatment & Body weight $\mathbf{( K g )}$ & Parity & Lactation days (days) \\
\hline Control & $612^{\mathrm{a}} \pm 17.5$ & $2.7 \pm 1.0$ & $73.0 \pm 9.9$ \\
EG1 & $579^{\mathrm{b}} \pm 14.8$ & $2.9 \pm 1.3$ & $75.9 \pm 9.9$ \\
EG2 & $604^{\mathrm{a}} \pm 17.4$ & $2.9 \pm 1.1$ & $75.3 \pm 8.5$ \\
EG3 & $604^{\mathrm{a}} \pm 16.9$ & $2.7 \pm 1.1$ & $78.0 \pm 9.4$ \\
\hline
\end{tabular}

Different small letters represent that was significant at $5 \%$ level. EG1, EG2 and EG3 mean the experimental group with 33, 67 and 100 g/day HWE added into Total Mixed Rations (TMR) diet. 
Table 2: Composition and nutrient level of Total Mixed Rations (TMR) as the basal diet for the dairy cows

\begin{tabular}{lccc}
\hline Ingredients & Content (\%) & Nutrient $^{\#}(\mathbf{g} / \mathbf{K g})$ & Level \\
\hline Corn silage & 37.30 & Dry matter & 486.00 \\
BSG & 16.90 & $\mathrm{CP}$ & 86.46 \\
Corn & 15.86 & $\mathrm{NDF}$ & 209.62 \\
Alfalfa hay & 8.40 & $\mathrm{ADF}$ & 109.75 \\
Wheat bran & 5.15 & $\mathrm{Mg}$ & 11.14 \\
Beet pulp & 4.60 & $\mathrm{Ca}$ & 6.95 \\
Soybean bran & 4.55 & $\mathrm{~K}$ & 4.75 \\
Chinese wild rye & 2.50 & $\mathrm{P}$ & 2.63 \\
Wheat middling & 0.52 & $\mathrm{Na}$ & 2.28 \\
DDGS & 2.42 & $\mathrm{Cl}$ & 2.62 \\
CaCO3 & 0.61 & VitaminA(IU/Kg) & 1076.41 \\
$\mathrm{NaHCO3}$ & 0.52 & Vitamin E (IU/Kg) & 4.36 \\
$\mathrm{NaCl}$ & 0.67 & $\mathrm{NEL} \mathrm{(MJ/Kg)}$ & 6.18 \\
\hline
\end{tabular}

${ }^{\text {"T}}$ The microelement contents of the TMR after calculated were as follows (mg/kg): S 753.50, Fe 130.79, Zn 19.01, Mn 12.63 and Cu 5.08. BSG: Brewer's grains; DDGS: dried distillers grains with solubles; NEL: net energy lactation; CP: Crude protein; NDF: neutral detergent fiber; ADF: acid detergent fiber.

\section{Sample collection and measurement}

On day $0,20,40$, and 60 of the experimental period, milk samples $(40 \mathrm{~mL})$ were collected three times daily at 0800,1400 and $2000 \mathrm{~h}$ using a portable vacuum milking machine (Kangyuan dairy machinery Co. Ltd., Nanjing, China). The milk samples were pooled (V/V/V 4:3:3 ratio) and then frozen at $-20{ }^{\circ} \mathrm{C}$ prior to analysis. All samples were analyzed for concentration of IgG, IgA and IgM using a colorimetric enzyme-linked immunosorbent assay (ELISA; Beijing Huaying Bioengineering Institute, Beijing, China) according to the instructions manufacturer's instructions. All absorbance values were calculated using a SpectraMax M2 microplate reader (Molecular Devices, USA).

Blood samples $(10 \mathrm{~mL})$ were collected via tail venipuncture before feeding on days $0,20,40$, and day 60, respectively. The blood samples were centrifuged at $3500 \times \mathrm{g}$ for $10 \mathrm{~min}$ to collect serum. The serum was then separated into several aliquots, frozen at $-20{ }^{\circ} \mathrm{C}$, and later analyzed for total antioxidant capacity (TAC), as well as super oxygen dismutase (SOD), malonaldehyde (MDA), and glutathione peroxidase (GSH-Px) levels using a colorimetric assay kit (Beijing Huaying Bioengineering Institute, Beijing, China). Serum concentrations of $\lg G, \lg A$, and $\operatorname{lgM}$ were measured by ELISA (Beijing Huaying Bioengineering Institute, Beijing, China) according to the manufacturer's instructions. All absorbance values were calculated using a SpectraMax M2 microplate reader (Molecular Devices, USA). All samples were tested in duplicate.

\section{Statistical analysis}

The study data were analyzed by general linear model repeated measure (GLMRM) of using Statistical Package for the Social Sciences SPSS for Windows (version 20.0, IBM, New York, USA). All data are shown as least-squares mean (LSM) \pm standard error of the mean (SEM). The measurements taken on different sampling days from the same cow were considered the repeated measure in the model. All data were compared using GLMRM, where the days were used as within-subject variable, and the treatments (Control, EG1, EG2 and EG3) were used as between-subject factors to examine the effects of treatments.

\section{RESULTS}

\section{Immunoglobulin concentration in milk}

The effects of HWE administration on the milk concentrations of $\lg G$, IgA, and $\lg M$ are shown in Figure 1.No significant effects of HWE on milk levels of $\lg G$, IgA and $\lg M$ were detected between control and the treatment groups at any time point analyzed $(p>0.05)$. Likewise, no interaction between time and treatments $(p>$ 0.05 ) was identified. Furthermore, no overall effects or significant differences were found in milk IgG, IgA, and $\lg M$ levels between the treatment groups at different time points. The results indicated that there was no obvious change in the milk concentrations of $\lg$, IgA, and IgM following the addition of HWE to the diet of the dairy cows. 

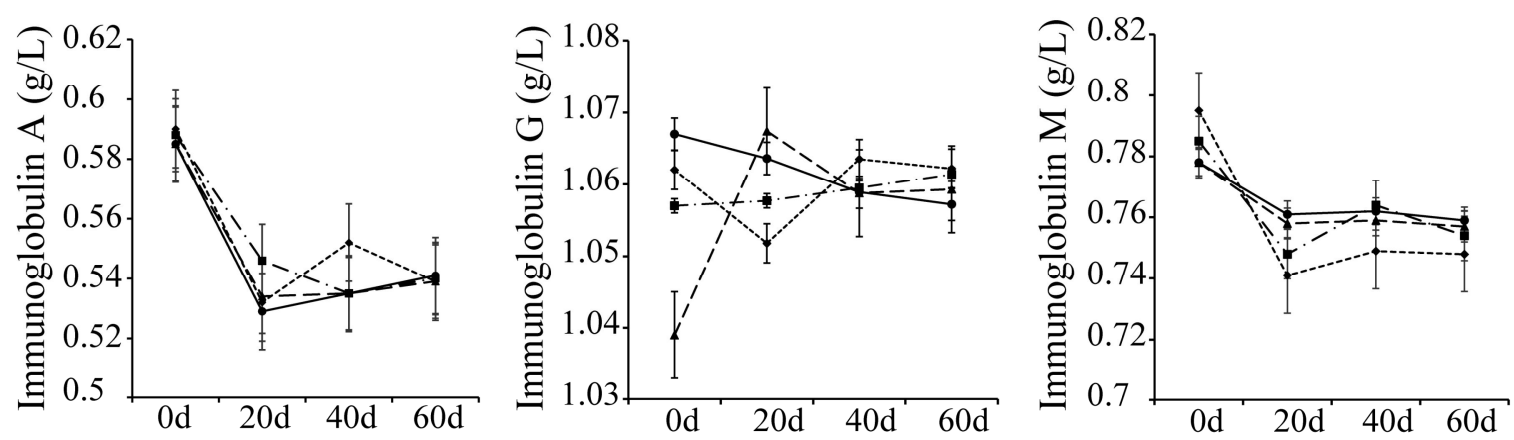

Figure 1: Mean values of $\operatorname{lgG}, \lg A$ and $\lg M$ in milk at various sampling stages. Note: Control = group for $0 \mathrm{~g} / \mathrm{d}$ HWE; EG1 = Test group 1 for 33 g/d HWE; EG2 = Test group 2 for 67g/d HWE; EG3 = Test group 3 for 100 g/d HWE; Control = •, EG1 = $\mathbf{\Delta}, E G 2=\mathbf{\square}, E G 3=\bullet$
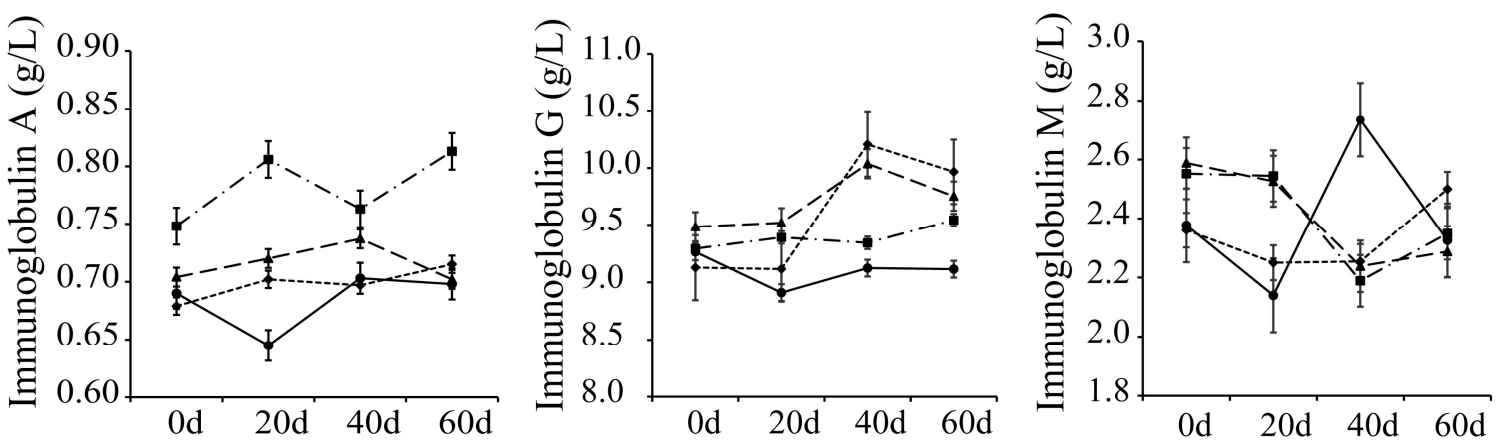

Figure 2: Mean values of IgG, IgA and Ig $M$ in serum at various sampling stages. Note: Control: The group for 0 g/d HWE, EG1: The experiment group 1 for $33 \mathrm{~g} / d$ HWE, EG2: The experiment group 2 for 67g/d HWE, EG3: The experiment group 3 for $100 \mathrm{~g} / \mathrm{d}$ HWE; Control: •, EG1:A, EG2:匹, EG3:

\section{Serum immunoglobulin concentration}

In the present study, the overall serum $\lg A$ concentration in the EG1, EG2 and EG3 groups were higher than corresponding concentrations in the control group $(p<0.01)$. According to Fig. 2 , the concentration of $\operatorname{IgA}$ in serum from the control group decreased at second time point (20 d), while the serum concentrations of $\operatorname{Ig} A$ in EG1, $E G 2$, and EG3 increased. No interaction between the sampling times and treatments were detected for serum IgG or IgM concentrations. However, serum IgG concentrations in the EG1, EG2, and EG3 groups were higher than corresponding levels in the control group following the administration of HWE. However, the differences were not marked, and indicated that the humoral immune response remained stable. As well, the serum IgG concentrations in every group were lower over the course of the study than the normal reported range (IgG, 17 $27 \mathrm{~g} / \mathrm{L} ; \lg \mathrm{A}, 0.1-0.5 \mathrm{~g} / \mathrm{L})$ [13].

\section{Serum antioxidant capacity}

The results revealed that there were significant differences in TAC among the control, EG1,
$E G 2$, and EG3 groups, and that TAC in the EG1 and EG3 groups was obviously higher than corresponding values in the control group $(p<$ 0.05). No significant differences in serum MDA, SOD, or GSH-Px concentrations were detected between the control and experimental groups ( $p$ $>0.05)$.

\section{DISCUSSION}

The results of the study suggest that the use of HWE as a dietary additive in dairy cows had no effect on $\lg G$, $\lg A$, or IgM concentrations in milk. Milk is rich in nutrients, including vitamins, protein, and fat, as well as immune components such as immunoglobulins. Immunoglobulins (i.e. $\lg$, IgA and IgM) are important biologically active milk protein. However the concentration of the various bovine immunoglobulins in serum and lacteal secretions varies according to the breed, age, health status, and the stage of lactation. Similarly, the content of various immunoglobulins in human breast milk varies according to the stage of lactation and the health of breast. IgG plays a predominant role in milk, and comprises between $80 \%$ and $90 \%$ of total concentration of milk immunoglobulins [14]. 

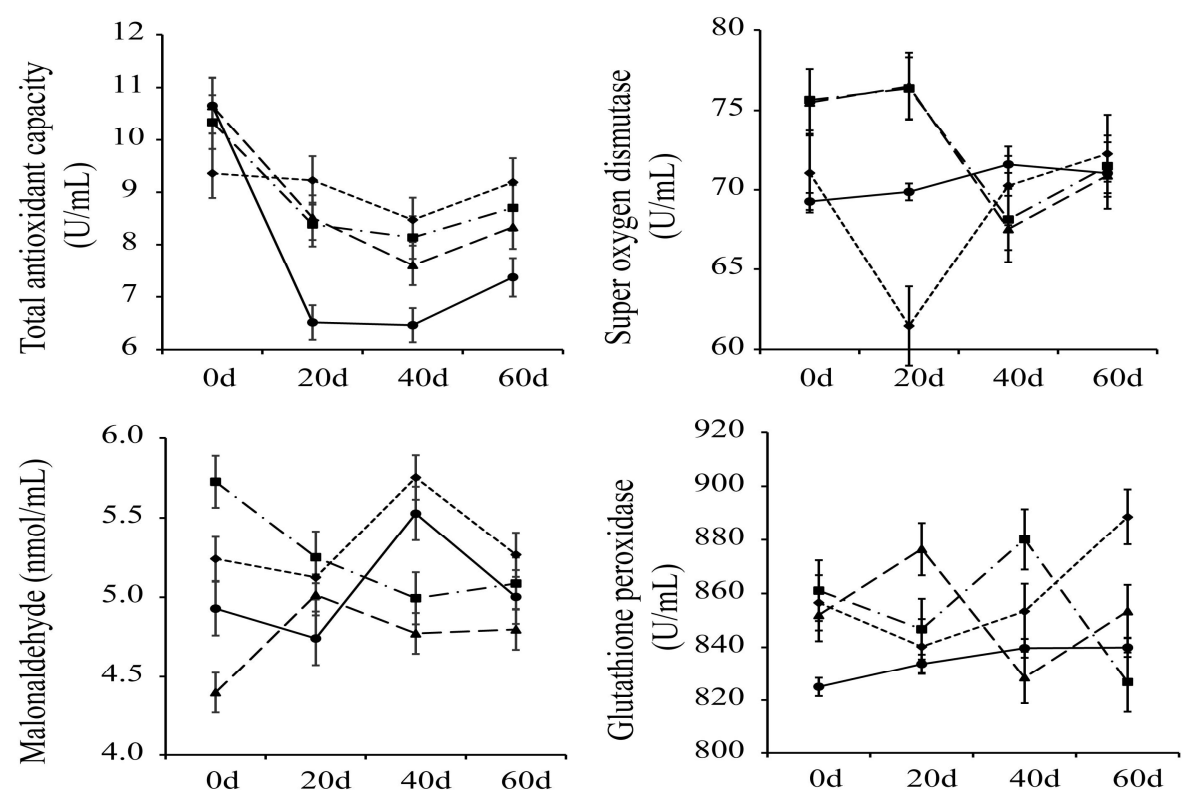

Figure 3: Effect of dietary HWE supplementation on serum concentrations of TAC, SOD, MDA and GSH-Px in dairy cows. Note: Control: The group for 0 g/d HWE, EG1: The experiment group 1 for $33 \mathrm{~g} / d$ HWE, EG2: The

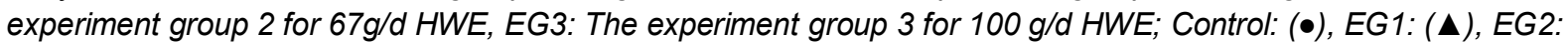
(घ), EG3: (»)

In the secretory epithelium of the bovine mammary gland, IgG is selectively transferred from serum into milk by a neonatal Fc receptormediated mechanism [15-17]. The IgG transport mechanism was first described for the movement of IgG from the serum to the mammary gland during colostrogenesis, but it was later established that the mechanism plays a more general role in the homeostatic regulation of albumin and IgG levels [17,18]. Further, the process involved in the transition of immunoglobulins from serum to the mammary gland is very complicated, and thus the effects of HWE administration on dairy cattle immunity requires further study.

In the current study, the resulting serum $\lg G, \lg A$, and IgM concentrations were similar to the serum IgG levels reported by Guo et al [19], but differed from a prior report that daidzein supplementation increased serum IgG levels in dairy cows [20].

Immunoglobulin $\mathrm{G}$ plays an important role in systemic immune response and is the serum primary antibody after the ingestion of food. Conversely, $\operatorname{IgA}$ is the major antibody in the mucosal immunity. Further, the main function of $\lg A$ is to neutralize pathogenic bacteria by interaction with nonspecific innate defense mechanisms. Immunoglobulin $\mathrm{M}$ is the primary antibody produced during the initial stage of antibody response. Further, both subclasses of IgG are present in notable concentrations in serum (IgG1 $11.2 \mathrm{mg} / \mathrm{ml}$, IgG2 $9.2 \mathrm{mg} / \mathrm{mL}$ ), whereas $\lg M$ and $\lg A$ are present in concentrations of approximately $3.0 \mathrm{mg} / \mathrm{mL}$ and $0.4 \mathrm{mg} / \mathrm{mL}$, respectively [21].

Gao et al [22] reported that the concentrations of $\lg$, IgM and IgA were increased when added the herbal compound as feed additive in the diet of dairy cows. Similarly, Zhang et al [23] also reported that the compound recipe of Chinese herbal medicines could significantly improve serum immunoglobulin concentrations and humoral immunity in mid lactation dairy cows. In the present study, the concentration of $\lg A$ was markedly higher in the experimental groups compared with the control group. Conversely, the concentrations of IgG and IgM were not influenced by supplementation with HWE, although slight increases in serum IgG levels were detected in the EG1, EG2, and EG3 groups compared with the control group. The results suggested that using HWE as a feed additive might enhance immunity in dairy cows, and subsequently improve milk quality. To our knowledge, investigations on the effects of HWE from SMSG on immune function in dairy cows are limited. Consequently, additional studies regarding the use of $\mathrm{HWE}$ as a food additive in dairy cattle are required.

In the present study, the serum antioxidant capacity was increased when HWE was used as a dietary additive in dairy cows, and the 
indications of this study are in accord with the results of a previous study that revealed the antioxidant capacity of a compound preparation of five Chinese herbal medicines [24].

Free radicals which are the normal products of metabolism, have very strong oxidative capabilities. Further, oxygen free radicals are the most abundant of free radicals in the body, and account for approximately $95 \%$ of the total amount of free radicals [25]. The presence of a large number of oxygen free radicals can cause damage to proteins, lipids, and nucleic acids, which results in damage to the body [26]. Thus, it is of great significance to improve the body's antioxidant capacity, and to promote the health and safety of animal products.

Lipid peroxidation (MDA) in serum is one of the important consequences of oxidative stress, and can be used as a reliable marker for evaluating the severity of oxidative stress [27]. SOD is involved in the conversion of oxygen radicals to peroxides, while GSH-Px is involved in removing the peroxides produced by the SOD enzyme, and converting the peroxides into water [28]. No statistically significant differences in serum concentrations of MDA, SOD, or GSH-Px were detected in the current study. However, the apparent decrease in MDA suggests a decrease in lipid peroxidation levels, while increases in SOD and GSH-Px levels revealed a potentially enhanced antioxidant capacity. Thus, the results indicate that the use of HWE as a dietary additive might improve antioxidant enzyme activity, effectively eliminate free radicals from the blood, and reduce damage caused by reactive oxygen species.

\section{CONCLUSION}

Overall, the data indicated that using HWE as a feed additive affects the concentration of serum $\lg \mathrm{A}$ and also enhances total antioxidant capacity. The use of HWE as a feed additive has good potential in animal husbandry, but requires further study.

\section{ACKNOWLEDGEMENT}

This study was financially supported by the China National Engineering Research Center of JUNCAO Technology (JCJJ13018 \& JCGG1406) and funded by the Projects of National Engineering Research Center of JUNCAO Technology, China (No. 2011FU125X12 \& No. 20123098).

\section{REFERENCES}

1. $X u J$ and Yang $Y$. Traditional Chinese medicine in the Chinese health care system. Health Policy 2009; 90: 133-139

2. Lei LS, Lin ZB. Effects of Ganoderma polysaccharides on the activity of DNA polymerase, $\alpha$ in spleenocytes and immune function in aged mice. Acta Pharmacol Sin 1993; 28:577-582

3. Zhang QH, Lin ZB. Study on antitumor activity and mechanism of Ganoderma polysaccharides B. China Journal of Integrated Traditional and Western Medicine 1999; 19:544-547

4. Lin ZB, editor. Lingzhi (Ganoderma): From Mystery to Science Beijing: Peking University Medical Press; 2009. p. 84-98

5. Streeter CL, Conway KE, Horn GW, Mader TL. Nutritional evaluation of wheat straw incubated with the edible mushroom, Pleurotus ostreatus. J Anim Sci. 1982; 54: 183-188.

6. Adamovieć M, Grubić G, Milenković I, Jovanocić R, Protić $R$, Sretenović $L$, Stoićević $L$. The biodegradation of wheat straw by Pleurotus ostreatus mushrooms and its use in cattle feeding. Anim Feed Sci Tech. 1998; 71: 357-362

7. Fazaeli $H$, Masoodi ART. Spent wheat straw compost of Agaricus bisporus mushroom as ruminant feed. Asian-Aust J of Anim Sci 2006; 19: 845-851.

8. Ayala M, González-Muñoz SS, Pinos-Rodríguez JM, Vázquez $C$, Meneses $M$, Loera $O$, Mendoza GD. Fibrolytic potential of spent compost of the mushroom Agaricus bisporus to degrade forages for ruminants. Afr J Microbiol Res 2011; 5: 241-249

9. Chen XB, Zhang SS, Lin ZX. Application effect of Juncao spent mushroom substrate as a feed in the dairy farming. Journal of Fujian Agriculture and Forestry University (Natural Science Edition) 2013; 42: 179183. (In Chinese)

10. Lin ZX, Zhang SS, Chen XB. Effects of water extract of Juncao spent Ganoderma lucidum substrate on production performance and blood biochemical parameters of dairy cows. Journal of Fujian Agriculture and Forestry University (Natural Science Edition) 2013; 42: 523-526. (In Chinese)

11. Lin ZX. 2012. Introductory JUNCAO Science. China National School of Administration Press, Beijing. 1025. (In Chinese)

12. Chinese Managements on Experimental Animal Care. Guide to the care and use of experimental animals. Beijing, Ministry of Science and Technology of the People's Republic of China, 2004

13. Yang HC, editor. Animal Immunology China Agricultural University Press, Beijing; 2003. p. 44-45

14. Elfstrand L, Lindmark-Månsson $H$, Paulsson M, Nyberg L, Akesson B. Immunoglobulins, growth factors and growth hormone in bovine colostrum and the effects of processing. Int Dairy J 2002; 12: 879-887. 
15. Kolb FA. Enineering immunity in the mammary gland. $J$ Mammary Gland Biol 2002; 7: 123-134.

16. Vaccaro $C$, Zhou J, Ober JR, Ward SE. Engineering the $F C$ region of immunoglobulin $G$ to modulate in vivo antibody levels. Nat Biotechnol 2005; 23: 1283-1288

17. Anderson LC, Chaudhury C, Kim J, Bronson LC, Wani AM, Mohanty S. Perspective-FcRn transports albumin: relevance to immunology and medicine. Trends Immunol 2006; 7: 343-348.

18. Roopenian $C D$, Akilesh S. FCRn: the neonatal FC receptor comes of age. Nat Rev Immunol 2007; 7:715-725.

19. Guo $X D$, Diao QY, Tu Y, Yan GL, Zhang NF, Deng KD, Ju CF, Zhao GQ, Wang YY, Gu XW, et al. Effect of Rutin Supplementation on Lactation Performance and Serum Parameters in Lactating Chinese Holstein Cows. Scientia Agricultura Sinia 2010; 43: 5137-5146

20. Yu B, Guo RF, Zhang SH. The application research of daidzein supplementation in diets of dairy cows. Sichuan Animal \& Veterinary Science, 2007; 7: 3233. (In Chinese).

21. Bulter JE. Passive immunity and immunoglobulin diversity. In Indigenous Antimicrobial Agent of Milkrecent Developments. IDF Special Issue 1994; 9404 4, pp 14-50.

22. Gao HX, Chen GS, Xu ZF. Effect of compound Chinese herbal medicine on growth performance and blood biochemical index of weanling pigs. Journal of Guizhou Agricultural Sciences 2010; 38(8): 146-148 (in Chinese)

23. Zhang QR, Li JG, Li XM. Effect of Chinese herb feed additives on immune function of dairy cows, Journal of Heilongjiang Animal Science and Veterinary Medicine 2004; 10:22-24 (In Chinese)

24. Li SX, Cao XZ, Zhong JB, Lu Y. Study on the comparison of the reducing ability and total phenolic content in several herbal antioxidant components. Journal of Anhui Agricultural Sciences 2008; 36(29):1275512756 (In Chinese)

25. Liu ZH, Yue BH. Toxic effect of the oxygen free radical on animal body. Journal of Animal medical progress 2005; 3:57 (In Chinese)

26. Kaufmann JA, Bickford PC, Taglialatela G. Free radicaldependent changes in constitutive nuclear factor kappa Bin the aged hippocampus. Neuroreport 2002; 13(15):1917

27. Halliwell $B$, Whiteman M. Measuring reactive species and oxidative damage in vivo and in cell culture: how should you do it and what do the results mean? Brit J Pharmacol 2009; 4: 231-255

28. Yu BP. Cellular defenses against damage from reactive oxygen species. Physiol Rev 1994; 1: 139-162. 